\title{
Preface
}

Neuropsychobiology

\section{Pharmaco-EEG, Pharmaco-Sleep and EEG-Based Personalized Medicine}

\author{
Marc Jobert ${ }^{\mathrm{a}}$ Martijn Arns ${ }^{\mathrm{b}, \mathrm{c}}$ \\ ${ }^{a}$ International Pharmaco-EEG Society (IPEG), Berlin, Germany; ${ }^{b}$ Research Institute Brainclinics, Nijmegen, and \\ 'Department of Experimental Psychology, Utrecht University, Utrecht, The Netherlands
}

Electrophysiological brain research has a long tradition going back as far as 1875 when the first report of the animal electroencephalogram (EEG) was published by Caton [1]. The first recordings from the human skull were reported by Berger [2] in the late 1920s and, not long thereafter, the intriguing world of the effects of drugs on the EEG opened up a scientific area of research known today as pharmaco-EEG. In 1957, Roth and colleagues reported EEG findings associated with a favourable treatment outcome to electroconvulsive therapy (ECT), laying the foundation of what we now consider as EEG-based personalized medicine [3]. The landscape significantly evolved with the advancement of computerized methods and the development of novel technologies for signal processing and quantification of the EEG and sleep polygraphy (polysomnography). More recently, during the last decade, many successful endeavours have improved the understanding and the sophisticated analysis of the electrophysiological brain as a three-dimensional organ.

In essence, pharmaco-EEG deals with the description and quantitative analysis of the effects of substances on the central nervous system (CNS) by means of neurophysiological and electrophysiological methods used within the framework of clinical and experimental pharmacology, neurotoxicology, therapeutic research and associated disciplines. Processing the EEG signals reveals the spontaneous synchronized postsynaptic neuronal activity of the cortex with high temporal resolution, thus providing a more direct measure of brain function than the haemodynamic or metabolic measures assessed by imaging techniques such as PMRI or FDG-PET. EEG is also unique in its direct applicability in both humans and animals. In totality, pharmaco-EEG encompasses a number of non-invasive methods that can be used routinely to assess the effects of pharmacological compounds on the CNS. Pharmaco-EEG can thus help further understanding of brain dynamics or pathology and can support (e.g. as a biomarker) the discovery, development and targeted application of drugs to treat CNS disorders.

The articles included in this issue of Neuropsychobiology are presented by the International Pharmaco-EEG Society (IPEG) to provide an overview of the techniques used in pharmaco-EEG, pharmaco-sleep and EEG-based personalized medicine research. Various aspects of pharmaco-EEG are covered, including EEG studies in animals with their translational applications (Jobert et al. $[4,5]$ ), advanced analysis of pharmaco-EEG in humans (Jobert and Wilson [6]) and pharmaco-sleep in humans (Anderer [7]). Further, the potential role of pharmaco-EEG and pharmaco-sleep for early decision-making in drug development and for the purpose of identifying whether compounds are active in the CNS is discussed (Jobert et al. [8]). The key outputs in this application are pharmacodynamic measures of the effects of centrally acting compounds. Additional theoretical aspects are discussed by Sander et al. [9], who demonstrate that detailed assessment of wakefulness and vigilance regulation offers a very exciting prospect in pharmaco-EEG research.

\section{KARGER 125}

(C) 2016 S. Karger AG, Base

0302-282X/16/0724-0137\$39.50/0
Dr. Marc Jobert

International Pharmaco-EEG Society (IPEG)

DE-13505 Berlin (Germany)

E-Mail publications@ IPEG-society.org 
In recent years there has been a rapid increase in the popularity of imaging techniques such as fMRI. However, the rate of publication of EEG and MEG studies has continued to increase during this time, with only the publication rates of PET and SPECT imaging reducing since the introduction of fMRI [10]. Combining imaging and other techniques with pharmaco-EEG in studies can, in many cases, provide added benefit as illustrated by Boeijinga [11], who discusses multimodal approaches including imaging, pharmaco-EEG, psychometrics and behavioural analysis. Another recent development has been an interest in high-frequency gamma EEG activity in addition to the traditionally acknowledged EEG frequencies spanning the delta, theta, alpha and beta ranges. This has paved the way for interesting and evolving developments in the processing and assessment of gamma EEG activity, which also have implications for pharmaco-EEG (Nottage and Horder [12]).

Finally, recent developments highlight the heterogeneity in psychiatric disorders, evidenced by the US National Institute of Mental Health (NIMH) Research Domain Criteria (RDoC) project, which is now a requirement for any funding proposals submitted to the NIMH. This has opened up a new avenue of pharmaco-EEG involving the prediction of treatment outcome which has become a prominent focus of the IPEG in recent years. Often referred to as 'precision medicine' or 'personalized medicine', this involves the development of biomarkers associated with response or non-response to pharmacological treatments. Stratifying patients based on such biomarkers can potentially reduce the well-known heterogeneity in imaging studies in psychiatry and result in new insights. This burgeoning field is reviewed by Olbrich et al. [13], with a focus on personalized medicine in depression and $\mathrm{ADHD}$, including recent insights from the large multicentre international study to predict optimized treatment in depression (iSPOT-D), which includes 1,008 depressed patients randomized to three different antidepressants.

We hope that the set of articles presented in this issue provides valuable updates on the broad, developing and expanding field of pharmaco-EEG research and thus will help promote the increased use of pharmaco-EEG. Last but not least, we hope to see you in Nijmegen (The Netherlands) in October 2016 for the next biennial IPEG conference (www.ipeg-society.org), where the most up-todate advances in this exciting field will be presented by renowned international speakers!

The 'International Pharmaco-EEG Society - Association for Electrophysiological Brain Research in Preclinical and Clinical Pharmacology and Related Fields' (IPEG) is a non-profit organisation established in 1980 in Berlin and is composed of scientists and researchers actively involved in electrophysiological brain research in preclinical and clinical pharmacology, neurotoxicology and related areas of interest. Guidelines for the recording and evaluation of pharmaco-EEG studies and of pharmacosleep studies have been published in this journal in 2012 and 2013, respectively $[14,15]$.

\section{References}

1 Caton R: The electric currents of the brain. $\mathrm{Br}$ Med J 1875;2:278.

-2 Berger H: Über das Elektrenkephalogramm des Menschen. Arch Psychiatr Nervenkr 1929;87:527-570

3 Roth M, Kay DW, Shaw J, Green J: Prognosis and pentothal induced electroencephalographic changes in electro-convulsive treatment; an approach to the problem of regulation of convulsive therapy. Electroencephalogr Clin Neurophysiol 1957;9:225-337.

-4 Jobert M, Drinkenburg WHIM, Ahnaou A, Ruigt GSF: Pharmaco-EEG studies in animals: a history-based introduction to contemporary translational applications. Neuropsychobiology 2015;72:139-150.

5 Jobert M, Drinkenburg WHIM, Ruigt GSF, Ahnaou A: Pharmaco-EEG studies in animals: an overview of contemporary translational applications. Neuropsychobiology 2015;72:151-164
6 Jobert M, Wilson FJ: Advanced analysis of pharmaco-EEG data in humans. Neuropsychobiology 2015;72:165-177.

7 Anderer P: Advanced analysis of pharmacosleep data in humans. Neuropsychobiology 2015;72:178-187.

8 Jobert M, Wilson FJ, Danjou P: Early decision-making in drug development: the potential role of pharmaco-EEG and pharmacosleep. Neuropsychobiology 2015;72:188-194.

-9 Sander C, Hensch T, Wittekind DA, Böttger D, Hegerl U: Assessment of wakefulness and brain arousal regulation in psychiatric research. Neuropsychobiology 2015;72:195205.

10 Smith K: Brain imaging: FMRI 2.0. Nature 2012;484:24.

-11 Boeijinga PH: Multimodal EEG recordings, psychometrics, and behavioural analysis. Neuropsychobiology 2015;72:206-218.
12 Nottage JF, Horder J: State-of-the-art analysis of high-frequency (gamma range) EEG in humans. Neuropsychobiology 2015;72:219228.

13 Olbrich S, van Dinteren R, Arns M: Personalized medicine: review and perspectives of promising EEG biomarkers in major depressive disorder and attention deficit hyperactivity disorder. Neuropsychobiology 2015;72: 229-240

14 Jobert M, Wilson FJ, Ruigt GSF, Brunovsky M, Prichep LS, Drinkenburg WHIM, et al: Guidelines for the recording and evaluation of pharmaco-EEG data in man - International Pharmaco-EEG Society (IPEG). Neuropsychobiology 2012;66:201-220.

15 Jobert M, Wilson FJ, Roth T, Ruigt GSF, Anderer P, Drinkenburg WHIM, et al: Guidelines for the recording and evaluation of pharmaco-sleep studies in man - International Pharmaco-EEG Society (IPEG). Neuropsychobiology 2013;67:127-167. 